\title{
Origin and accumulation mechanisms of Wufeng-Longmaxi shale gas in the Sichuan Basin, China
}

\author{
J.R. BEAGLE ${ }^{12}$, C. CAO ${ }^{3}$, Y.WANG ${ }^{2}$, G. HOLLAND ${ }^{4}$,Z. \\ $\mathrm{ZHOU}^{1}$
}

${ }^{1}$ LEC, Lancaster University, Lancaster, LA1 4YQ, UK

${ }^{2}$ State Key Laboratory of Organic Geochemistry, Guangzhou Institute of Geochemistry, Chinese Academy of Sciences, Guangzhou, 510640, China

${ }^{3}$ Key Laboratory of Petroleum Resources, Institute of Geology and Geophysics, Chinese Academy of Sciences, Lanzhou, 730000, China

${ }^{4}$ Department of Earth and Environmental Sciences, The University of Manchester, M13 9PL, UK

The Sichuan Basin, in the SW of China, is acknowledged to be the cradle and future of China's natural gas industry, having become one of the leading areas for unconventional shale gas exploration in recent years. The high-quality, organic-rich, Upper Ordovician Wufeng and Lower Silurian Longmaxi marine shales ( $98 \%$ methane), in particular, exhibit ideal characteristics such as stable vertical and lateral distribution. However, a detailed understanding of the essential geochemical characteristics of these shales is still lacking. Compositional variability and fluid migration dynamics are less well constrained. In this study, we present $\mathrm{CH}_{4}$ gas composition, stable \& noble gas isotopic data with the purpose of understanding the origin and migration history associated with the Wufeng-Longmaxi shales in the Fuling, Weiyuan, Changning and Zhaotong gas fields of the Sichuan Basin, China.

Noble gases are valuable geo-dynamic fluid flow tracers that can provide a set of conservative tools capable of defining the physical conditions that affect crustal fluid systems. 24 gas samples were collected from producing wells targeting the Wufeng-Longmaxi fm. within the central, eastern and southern margins of the Sichuan Basin. ${ }^{3} \mathrm{He} /{ }^{4} \mathrm{He}$ ratios range between $0.0037 \mathrm{R}_{\mathrm{a}}$ to $0.038 \mathrm{R}_{\mathrm{a}}\left(\mathrm{R}_{\mathrm{a}}=\right.$ atmospheric $\left.{ }^{3} \mathrm{He} /{ }^{4} \mathrm{He}\right)$, indicating a predominantly crustal radiogenic signature. ${ }^{40} \mathrm{Ar} /{ }^{36} \mathrm{Ar}$ ratios are higher $(\leq 5817)$ than atmospheric values (295.5). Water-derived ${ }^{20} \mathrm{Ne} /{ }^{36} \mathrm{Ar}$ ratios correlate well with radiogenic ${ }^{4} \mathrm{He} /{ }^{40} \mathrm{Ar}$ ratios, and it is, therefore, likely that they are influenced by common processes. Desorption processes may explain a linear increase in water derived ${ }^{84} \mathrm{Kr} /{ }^{36} \mathrm{Ar}$ ratios with ${ }^{130} \mathrm{Xe} /{ }^{36} \mathrm{Ar}$ ratios.

Preliminary data suggests groundwater plays a key role in both the generation and migration of these shale gases. Adsorption, desorption and oil-gas-water phase interactions largely govern the geochemical characteristics in these unconventional shale gas reservoirs in the central, eastern and southern margins of the Sichuan Basin. 